\title{
Investigation of Performance Envelope for Phenolic Impregnated Carbon Ablator (PICA)
}

\author{
Parul Agrawal, ${ }^{1}$ Dinesh Prabhu ${ }^{2}$ \\ AMA, Inc. at NASA Ames Research Center, Moffett Field, CA, 94035 \\ Frank S. Milos, ${ }^{3}$ Mairead Stackpoole ${ }^{4}$ \\ NASA Ames Research Center, Moffett Field, CA, 94035
}

\begin{abstract}
The present work provides the results of a short exploratory study on the performance of Phenolic Impregnated Carbon Ablator, or PICA, at high heat flux and pressure in an arcjet facility at NASA Ames Research Center. The primary objective of the study was to explore the thermal response of PICA at cold-wall heat fluxes well in excess of $\mathbf{1 5 0 0}$ W/cm ${ }^{2}$. Based on the results of a series of flow simulations, multiple PICA samples were tested at an estimated cold wall heat flux and stagnation pressure of $1800 \mathrm{~W} / \mathrm{cm}^{2}$ and 130 kPa, respectively. All samples survived the test, and no failure was observed either during or after the exposure. The results indicate that PICA has a potential to perform well at environments with significantly higher heat flux and pressure than it has currently been flown.
\end{abstract}

\begin{tabular}{|c|c|c|c|c|c|}
\hline \multicolumn{6}{|c|}{ Nomenclature } \\
\hline CFD & $=$ & Computational Fluid Dynamics & $D_{b}$ & $=$ & Base diameter \\
\hline CT & $=$ & Computed Tomography & $H_{\text {bulk }}$ & $=$ & Bulk total enthalpy \\
\hline DPLR & $=$ & Data Parallel Line Relaxation code & $H_{\mathrm{CL}}$ & $=$ & Centerline total enthalpy \\
\hline FIAT & $=$ & $\begin{array}{l}\text { Fully Implicit Ablation Thermal } \\
\text { response code }\end{array}$ & $K$ & $=$ & $\begin{array}{l}\text { Constant of proportionality in a } \\
\text { simplified Fay-Riddell correlation }\end{array}$ \\
\hline IHF & $=$ & Interaction Heating Facility & $p_{\text {stag }}$ & $=$ & Stagnation point pressure \\
\hline IM & $=$ & Inspiration Mars & $q_{\text {stag }}$ & $=$ & Stagnation point heat flux \\
\hline IR & $=$ & Infrared & $R_{b}$ & $=$ & Base radius \\
\hline MSL & $=$ & Mars Science Laboratory & $R_{c}$ & $=$ & Corner (or shoulder) radius \\
\hline MSR & $=$ & Mars Sample Return & $R_{\text {eff }}$ & $=$ & Effective radius \\
\hline PICA & $=$ & $\begin{array}{l}\text { Phenolic Impregnated Carbon } \\
\text { Ablator }\end{array}$ & $R_{n}$ & $=$ & Nose radius \\
\hline TPS & $=$ & Thermal Protection System & & & \\
\hline
\end{tabular}

\section{Introduction}

$\mathrm{T}$ hermal protection systems (TPS) for capsules that execute atmospheric entries at hyperbolic velocities (in excess of $11 \mathrm{~km} / \mathrm{s}$ at Earth) are based on ablative materials. One class of ablative materials is low density, Phenolic Impregnated Carbon Ablator, or PICA, which is of particular interest, because its low density implies a relatively light TPS or heatshield, and hence, a lower entry mass of the capsule. During entry heating, the phenolic phase pyrolyzes and the pyrolysis gas blows the hot boundary layer away from the wall. A charred region composed of carbon is left behind after pyrolysis is complete. Any further heating causes the carbon to either oxidize, erode or sublimate, with consequent surface recession.

PICA was originally developed for the NASA Stardust mission, which successfully returned samples of comet material back to Earth in $2006 .{ }^{1}$ During reentry of the Stardust capsule at roughly $13 \mathrm{~km} / \mathrm{s}$ the PICA heatshield (built

\footnotetext{
${ }^{1}$ Senior Research Scientist, Thermal Protection Materials Branch, Mail Stop 234-1. Senior Member AIAA.

${ }^{2}$ Senior Staff Scientist, Entry Systems and Technology Division, Mail Stop 229-1. Associate Fellow AIAA.

${ }^{3}$ Aerospace Engineer, Thermal Protection Materials Branch, Mail Stop 234-1. Senior Member AIAA.

${ }^{4}$ Senior Research Scientist, Thermal Protection Materials Branch, Mail Stop 234-1.
} 
in a monolithic construction) was exposed to an estimated peak heat flux of $1000 \mathrm{~W} / \mathrm{cm}^{2}$, and a stagnation pressure of $28 \mathrm{kPa}(0.28 \mathrm{~atm}){ }^{2}$ A slightly different formulation of PICA was used as the heatshield (in a tiled construction) as shown in Figure 1, for the Mars Science Laboratory (MSL) spacecraft, which carried the Curiosity rover to Mars. ${ }^{3}$ MSL did not experience the same level of heating as Stardust. PICA is currently the baseline heatshield material for the OSIRIS-REx sample return mission ${ }^{4}$ scheduled to launch in 2016. Furthermore, SpaceX uses a variant called PICA-X on its Dragon spacecraft that ferries cargo to and from the International Space Station. ${ }^{5}$

Since the successful demonstration of PICA's flight performance up to $1000 \mathrm{~W} / \mathrm{cm}^{2}$ and 0.28 atm of pressure, several subsequent successful tests in the arcjet facility at NASA Ames Research Center (ARC) have shown PICA material to be capable of handling heat fluxes up to $1600 \mathrm{~W} / \mathrm{cm}^{2}$, at surface pressures up to $130 \mathrm{kPa}{ }^{6}$ If indeed PICA would exhibit no failure at heat fluxes and pressures higher than previously measured, it could become viable as a heatshield material for other missions, e.g., the Inspiration Mars (IM) mission concept of Dennis Tito as well as Comet Surface Sample Return (CSSR) missions. The Inspiration Mars mission concept explored the feasibility of sending two people on a fast fly-by of Mars in 2018 with a propulsion-free return to Earth at roughly $14 \mathrm{~km} / \mathrm{s} .{ }^{7}$ Results of the mission study showed that the entry capsule would experience a peak heat flux of the order of 2000 $\mathrm{W} / \mathrm{cm}^{2}$. The questions then are: (1) can standard PICA be tested at higher than $1500 \mathrm{~W} / \mathrm{cm}^{2}$ heatflux in the arcjets and (2) in the event of failure of the standard material, could it be densified - at the surface or through the thickness - to extract ablative performance without material failure?

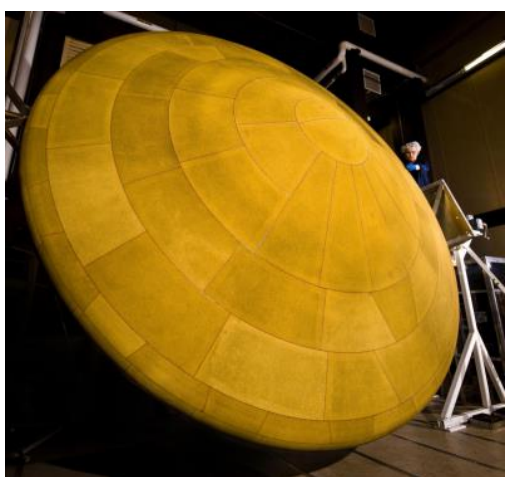

Figure 1. MSL PICA heatshield

Toward this end, tests were performed in the arc-heated flow through a $15 \mathrm{~cm}(6$ inches) nozzle of the $60 \mathrm{MW}$ Interaction Heating Facility (IHF) at NASA ARC. The primary objective of these tests was to explore the performance of standard PICA and its denser variants at high heat fluxes (in excess of $1500 \mathrm{~W} / \mathrm{cm}^{2}$ ) and high pressures (in excess of $1 \mathrm{~atm}$ ). The emphasis of the present paper is solely on the performance of standard PICA. The sections that follow provide details of the test design and the key findings from the test.

\section{Arc-Jet Model Design and Pre-test Aerothermal Analysis}

The overall geometry of an arcjet stagnation test article consists of two major parts - a leading portion made of the TPS material to be tested, and a model holder made of graphite; the model holder is attached to the water-cooled sting of the arc jet facility. In order to optimize the design for test sample and achieve the desired test environments pre-test aerothermal analysis was performed. The test sample (TPS material) diameter was set to $5 \mathrm{~cm}$ (2 inches) to achieve heat flux values $>1500 \mathrm{~W} / \mathrm{cm}^{2}$. While we could have used smaller samples to achieve even higher heatflux, the sidewall heating would have been significant and for the present tests we decided to go with $5 \mathrm{~cm}$ diameter. The holder design and material selection was also critical to avoid any undesired failure events (e.g. sample falling off the holder) either during or immediately after the plasma exposure. Figure 2 shows the various axisymmetric geometries evaluated computationally as part of the aerothermal design phase. The three categories of geometrical considerations in the aerothermal design are shown in Table 1.

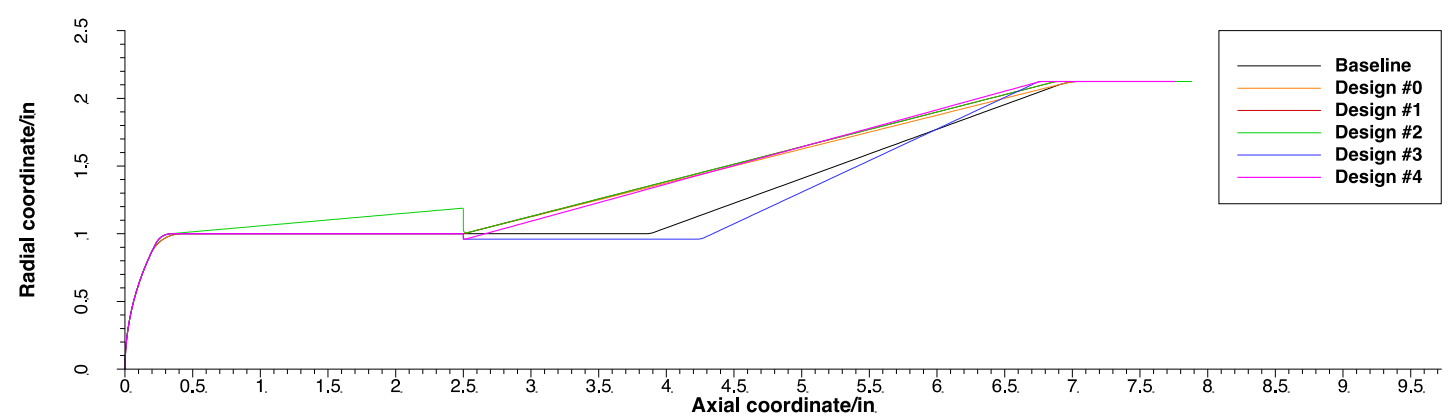

Figure 2. Candidate axisymmetric geometries evaluated in the aerothermal design phase. The overall geometry consists of two pieces - a leading portion made of the material to be tested, and a model holder made of graphite. 
Table 1. Geometrical considerations in aerothermal design of the test article

\begin{tabular}{|c|c|c|}
\hline & Primary Design Variables & Comments \\
\hline \multirow[t]{4}{*}{ TPS material } & $\begin{array}{l}\text { Radius of curvature of the } \\
\text { exposed face }\end{array}$ & $\begin{array}{l}\text { Curvature is required to keep the heat flux high } \\
\text { at the stagnation point; a flat-faced article will } \\
\text { experience lowest heating at the stagnation } \\
\text { point }\end{array}$ \\
\hline & Shoulder radius & $\begin{array}{l}\text { The radius of the shoulder has an influence on } \\
\text { the stagnation point heat flux (work of Zoby } \\
\text { and Sullivan }{ }^{8} \text { ); the smaller the shoulder } \\
\text { radius, the lower the stagnation point heating. }\end{array}$ \\
\hline & Angle of the side wall & $\begin{array}{l}\text { This variable is driven by sidewall heating and } \\
\text { consequent influence on any embedded } \\
\text { thermocouple; a sidewall angle of } 0^{\circ} \text { (cylinder) } \\
\text { yields a low heat flux distribution along the } \\
\text { wetted length. }\end{array}$ \\
\hline & Length of the test article & $\begin{array}{l}\text { This variable is driven by the requirement that } \\
\text { there be enough virgin material left to be able } \\
\text { to clearly discern char and density change over } \\
\text { the depth (thickness) of the material. }\end{array}$ \\
\hline \multirow[t]{2}{*}{ Graphite holder } & Base diameter & This variable is fixed by the test facility. \\
\hline & Ramp angle & $\begin{array}{l}\text { The taper angle of the graphite holder is } \\
\text { determined by the level of axial flow } \\
\text { separation at the foot of the ramp; although } \\
\text { flow separation provides some heating relief } \\
\text { over the length of the separated flow region, } \\
\text { the holder will experience locally enhanced } \\
\text { heating at the point of impingement of the } \\
\text { shear layer. }\end{array}$ \\
\hline Test Material-Holder interface & Step height & $\begin{array}{l}\text { A backward facing step is necessary to force } \\
\text { axial flow separation; the step height is } \\
\text { determined by the size of the separation } \\
\text { bubble. Furthermore, a small gap between the } \\
\text { test material and graphite holder is necessary } \\
\text { to account for disparity in thermal expansion of } \\
\text { the two parts. The size of the gap is driven by } \\
\text { thermal-structural considerations. }\end{array}$ \\
\hline
\end{tabular}

As mentioned earlier, $15 \mathrm{~cm}$ (6 inches) exit diameter nozzle of the $60 \mathrm{MW}$ IHF was chosen to achieve highest possible heating environment on the test article with that nozzle. For heater settings of $6000 \mathrm{~A}$ of current and a mass flow rate of $0.85 \mathrm{~kg} / \mathrm{s}$, nozzle computations were performed using the analysis procedure developed by Prabhu et al. ${ }^{9}$ This procedure uses the NASA flow solver, DPLR, ${ }^{10}$ as the main computational engine. DPLR solves the equations governing the flow of a gas mixture $\left(\mathrm{N}_{2}, \mathrm{O}_{2}, \mathrm{NO}, \mathrm{N}, \mathrm{O}\right.$, and $\mathrm{Ar}$ for the IHF) in thermochemical nonequilibrium. From the nozzle free jet solution, flow variables - mass density, velocity, temperatures (translational and vibrational), and mass fractions of the component species - were extracted at a point on the nozzle axis and $10 \mathrm{~cm}$ (4 inches) from the exit plane of the nozzle. These flow variables were used as uniform freestream conditions for the various candidate test article geometries. Computations for the test article were performed with two different wall boundary conditions: (a) wall temperature fixed at $400 \mathrm{~K}$ to mimic a calorimeter simulation, and (b) wall temperature allowed to float with imposition of radiative equilibrium (albeit without conduction through the thickness).

Contours of Mach number in the pitch plane of each of the six candidate geometries are shown in Figure 3. The contour plots provide a qualitative picture of the flow. The plots clearly show the influence of the ramp angle of the graphite holder - the steeper the ramp angle (Baseline and Design \#3), the larger the region of axially separated flow. A shallow ramp for the model holder ensures the flow stays attached on the test coupon, and increases sidewall heating. 
The surface pressure and heat flux distributions (Figure 4) for each of the configurations give a quantitative picture of the influence of various geometric parameters of the test models. Results of these pre-test computations showed that it might be possible to achieve a cold-wall heat flux of $2000 \mathrm{~W} / \mathrm{cm}^{2}$ (at a pressure of $1.4 \mathrm{~atm}$ ) at the stagnation point of the test article. This predicted heat flux is a $25 \%$ increase over the cold-wall value of $1600 \mathrm{~W} / \mathrm{cm}^{2}$ (at a pressure of $1.2 \mathrm{~atm}$ ) reported by Beerman and Stackpoole. ${ }^{6}$

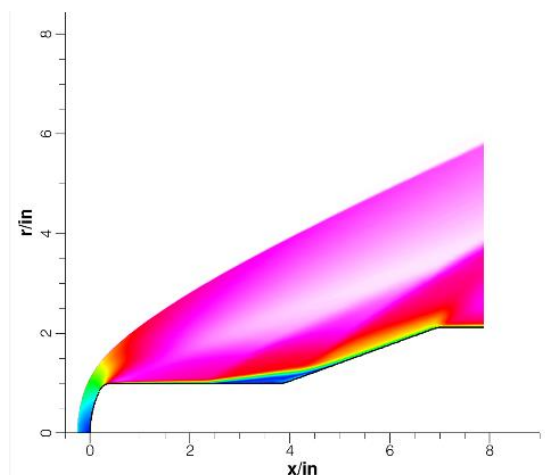

(a) Baseline

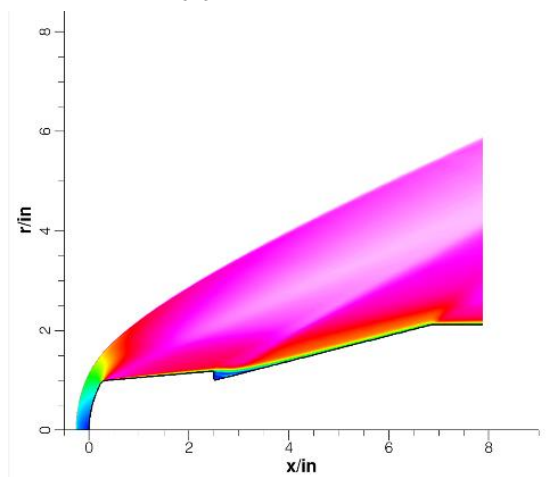

(d) Design \#2

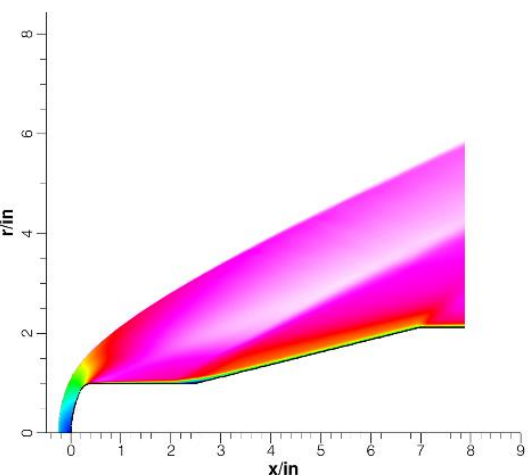

(b) Design \#0

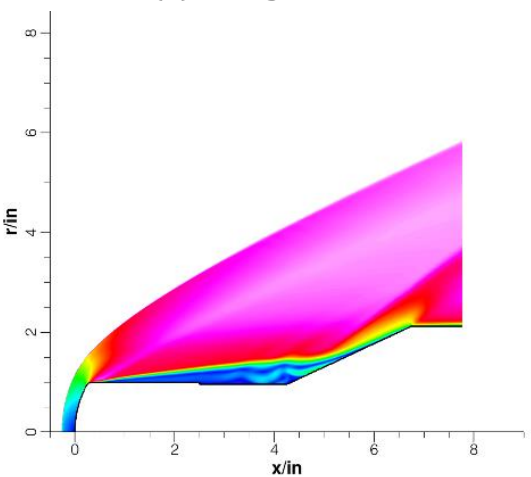

(e) Design \#3

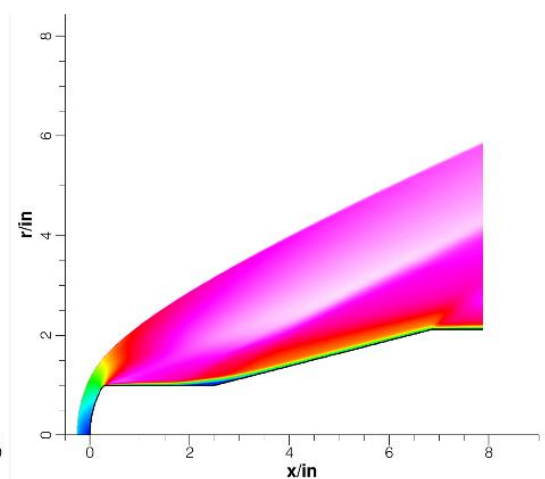

(c) Design \#1

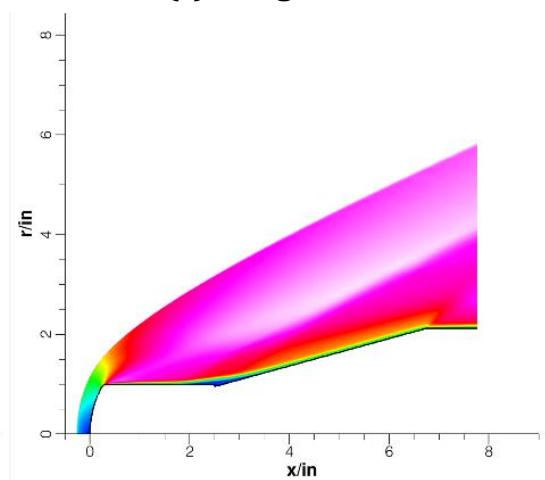

(f) Design \#4

Figure 3. Contours of Mach number in the pitch plane of candidate geometries. Axial flow separation is the largest for the steeper taper angles of the graphite holder.

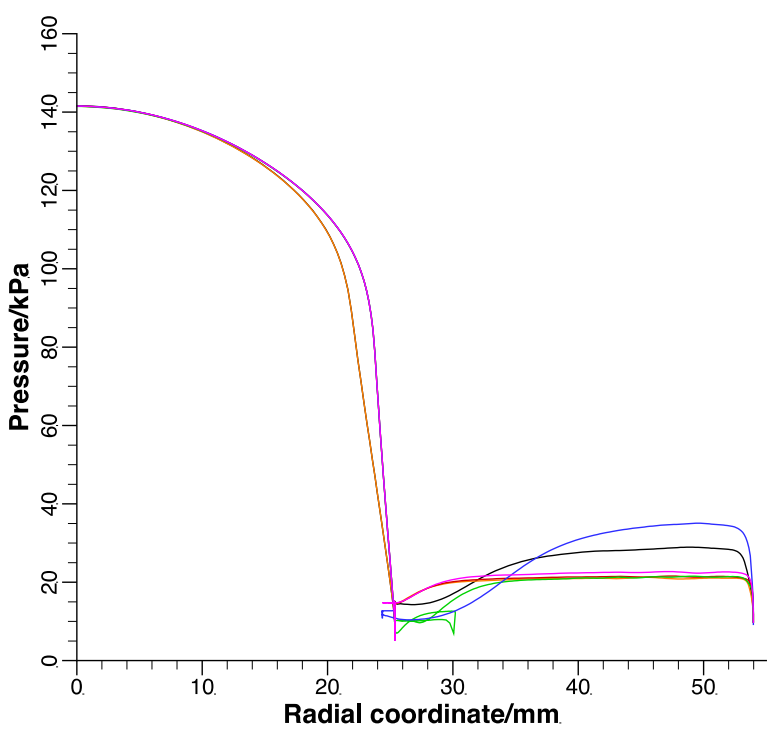

(a) Pressure

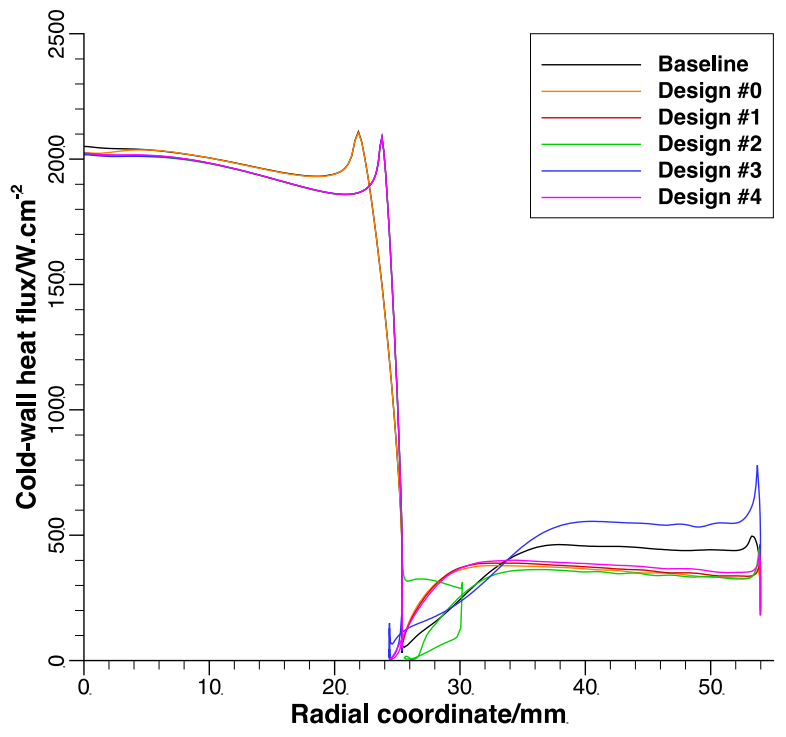

(b) Cold-wall heat flux 
Figure 4. Surface distributions of: (a) pressure, and (b) cold-wall heat flux for the 6 candidate geometries considered in the aerothermal design phase. Two of the configurations, designated as Baseline and Design \#3, have significant axial flow separation at the foot of ramp and the high heating $\left(\geq 400 \mathrm{~W} / \mathrm{cm}^{2}\right)$ over the graphite holder.

The candidate geometry designated as Design \#4 (see Figure 3) was selected as the final shape to be tested, and several models were constructed for tests in the IHF. The test coupon of $5 \mathrm{~cm}$ ( 2 inches) cylindrical diameter had a truncated spherical section with a radius of curvature of $5 \mathrm{~cm}$ ( 2 inches) and a shoulder radius of $0.64 \mathrm{~cm}(0.25$ inch); an iso-q body has its frontal radius of curvature the same as its base diameter, i.e., $R_{n}=D_{b}$. The entire test coupon was $6.4 \mathrm{~cm}$ (2.5 inches) long. The graphite holder had a taper angle of $15.3^{\circ}$, and at the test coupon-graphite holder interface there was a small rearward facing step of $1.3 \mathrm{~mm}(50 \mathrm{mil})$. The test coupon was attached to a graphite holder with help of 3 graphite pins and Graphi-Bond 551-RN (a high temperature graphite adhesive) at the interface, and the graphite holder, in turn, was connected to a water-cooled copper back plate to prevent the graphite holder from overheating. The overall length of the test articles (including the holder) was approximately $20 \mathrm{~cm}$ (7.8 inches). A dimensioned section of the entire test article and its interface to the facility sting are shown in Figure 5. The assembly of the various components of the test article is shown in Figure 6.

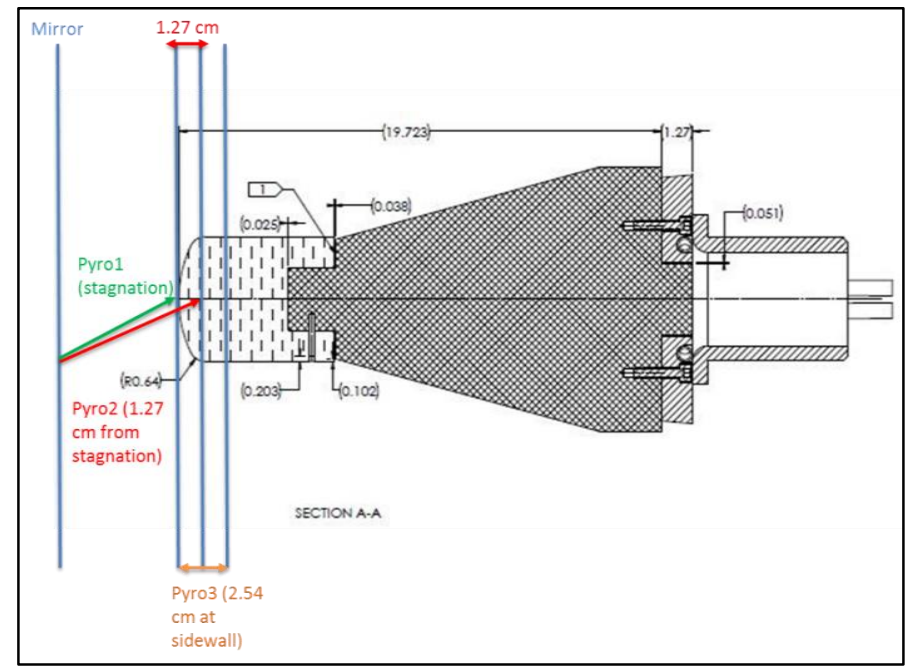

Figure 5: Model dimensions (cm) and pyrometer locations.

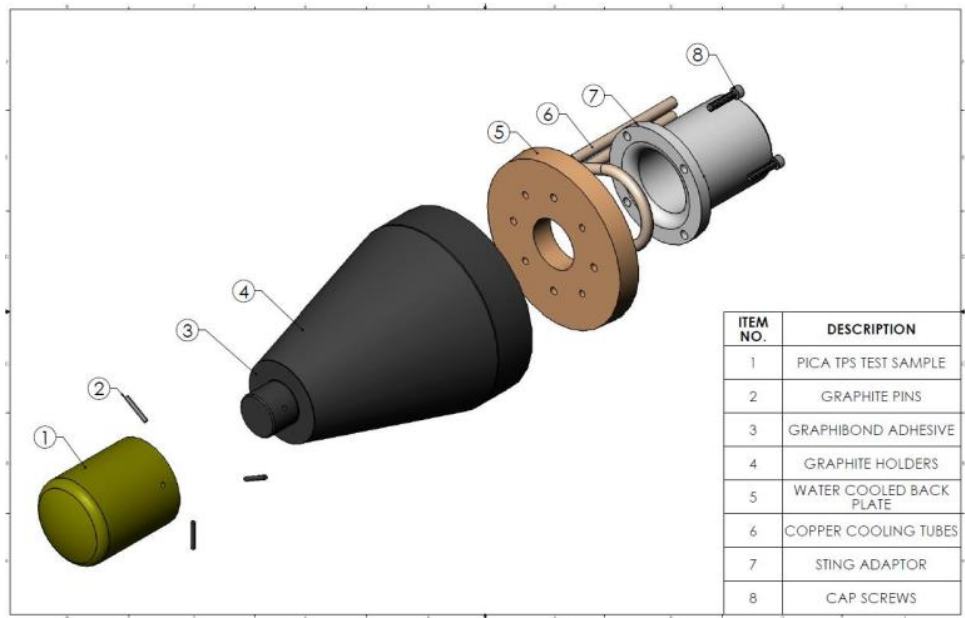

Figure 6: Components and assembly of test Article

\section{Pre-test Thermal Response Analysis}

The predicted aerothermal environments - surface pressure, heat transfer coefficient (heat flux divided by the difference between the edge and wall enthalpies), and recovery enthalpy - were then used as boundary conditions in 
material thermal response computations code, $F I A T,{ }^{11}$ to estimate the time of exposure (to the arc-heated stream) required to recess the test material by $2.5 \mathrm{~cm}(1 \mathrm{inch})$ at the stagnation point. Surface thermochemical interactions and blowing effects were incorporated in the material-response code by use of ablation tables or dynamic chemistry, a surface energy balance with heat transfer coefficient, and a blowing reduction parameter. Further details on this coupling methodology may be found in the work of Milos and Chen. ${ }^{12}$

It should be noted that for most arcjet tests with an iso-q shaped sample, the surface environments predicted by DPLR are assumed constant over the time of exposure. However, if shape change or total recession are large, then the surface pressure and heat flux values and distributions may change significantly, in which case a second DPLR solution for the ablated shape at the recessed distance from the nozzle exit is also recommended. The initial and final environments then are interpolated in time for the material response computations. A different boundary condition, which allows radiation to the environment but no ablation, is used for the cool-down period after the test article is taken out of the arc-heated stream. While there is no imposed heat flux on the test article, the internal processes of heat conduction and pyrolysis continue during the cool-down period.

The FIAT calculations for pre-test predictions for this test were performed using the nominal aerothermal environment, and also with a $\pm 10 \%$ scaling factor applied to the heat transfer coefficient. This factor is considered to be the minimum uncertainty of the arcjet environment. Figure 7 presents the predicted stagnation point recession histories for these three heating levels for the pre-test environment from Figure 4. At high heat flux, the recession rate of PICA is relatively steady. Based on these predictions, an exposure of duration of 20 seconds was proposed for the test series.

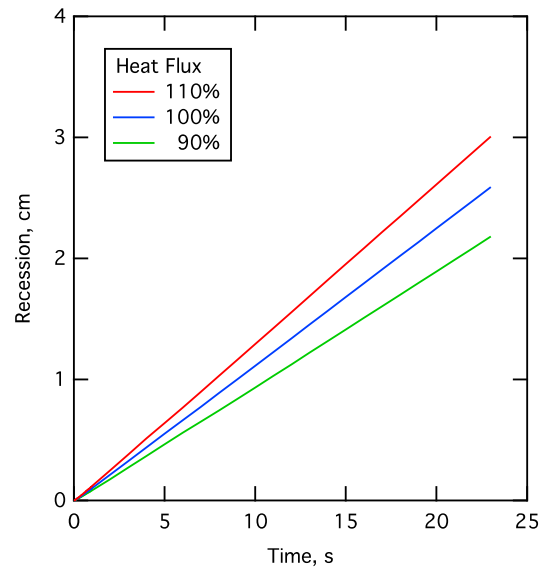

Figure 7. Predicted recession for pre-test environment with $\pm 10 \%$ variation in heat transfer coefficient.

\section{Test Environments and Instrumentation}

The nominal arcjet conditions, based on the pre-test analysis and the historical data collected on the facility parameters, are listed in Table 2. The maximum possible heat flux on the sample was obtained by operating the arc heater at near maximum current and flow rates. The real time measurement of the centerline heat flux values was attempted by using $51 \mathrm{~mm}$ iso-q calorimeters (identical to test samples) and $102 \mathrm{~mm}$ (4-inch) hemispherical calorimeter. The stagnation and sidewall surface temperature of the test samples were measured using optical pyrometers. Three different pyrometers were used for temperature measurements. The positions of pyrometers are shown in Figure 5. The first pyrometer was focused on the stagnation surface. The second pyrometer was focused $1.27 \mathrm{~cm}(0.5$ inches) away from the stagnation surface to the depth where surface densification ends. The third pyrometer was placed $2.5 \mathrm{~cm}$ away from the stagnation surface, to get measurements at the sidewall. Surface temperature measurements using a fibercoupled optical-emission spectrometer was also attempted during the test. In addition, an infra-red video was used to observe sidewall and stagnation surface temperature of the model. High definition video cameras were used to acquire videos during the arcjet exposure at various locations of the test samples. Pre- and post-test photographs of the test articles were also obtained.

The measured stagnation pressure and heat flux can be used to infer the total enthalpy along the central streamline of the flow using a simplified version of the Fay-Riddell correlation. ${ }^{13}$ The simplified correlation for a cold wall is:

$$
q_{\text {stag }}=K \frac{\sqrt{p_{\text {stag }}}}{\sqrt{R_{\text {eff }}}} H_{\mathrm{CL}}
$$


where the constant $K$, which depends on the mixture composition, is taken from the work of Zoby, ${ }^{14}$ and $R_{\text {eff }}$ is the effective hemispherical radius of a non-hemispherical blunt body. The effective radius depends on the ratios $R_{n} / R_{b}$ and $R_{c} / R_{b}$, where $R_{b}, R_{n}$, and $R_{c}$ are the base, nose, and shoulder (corner) radius, respectively, of the test coupon, and the value is determined from the work of Zoby and Sullivan. ${ }^{8}$ In the present work, the effective radius of the $51 \mathrm{~mm}(2$ inches) iso-q calorimeter is $45.4 \mathrm{~mm}$; the effective radius of a $102 \mathrm{~mm}$ (dia) hemispherical calorimeter is the same as its geometric radius, i.e., $51 \mathrm{~mm}$.

The simplified correlation in Eq. 1 can be used to determine the consistency of heat measurements made by two different calorimeters at the same flow condition. Applying Eq. 1 to the hemispherical and iso-q calorimeters, and taking the ratio of the two expressions, one has:

$$
\frac{q_{\text {stag,iso-q }}}{q_{\text {stag,hemi }}}=\frac{\sqrt{R_{\text {hemi }}}}{\sqrt{R_{\text {eff,iso-q }}}}
$$

Using the radii of the two calorimeters in Eq. 1, the ratio of heat fluxes is 1.06, i.e., the $51 \mathrm{~mm}$ iso-q calorimeter will measure $6 \%$ higher heat flux than the $102 \mathrm{~mm}$ hemispherical calorimeter at the same flow condition, a useful result that will be used later in post-test analysis.

Table 2: Target Arc-jet environments for test

\begin{tabular}{|c|c|c|c|c|c|c|c|c|c|}
\hline Facility & Nozzle & $\begin{array}{c}\text { Cold-Wall } \\
\text { Heat Flux } \\
(2-\text { in iso-q) } \\
\left(\mathrm{W} / \mathrm{cm}^{2}\right)\end{array}$ & $\begin{array}{c}\text { Stagnation } \\
\text { Pressure } \\
\quad(\mathrm{kPa})\end{array}$ & $\begin{array}{l}\text { Centerline } \\
\text { Enthalpy } \\
(\mathrm{MJ} / \mathrm{kg})\end{array}$ & $\begin{array}{l}\text { Main } \\
\text { Air } \\
(\mathrm{g} / \mathrm{s})\end{array}$ & $\begin{array}{c}\text { Add } \\
\text { Air } \\
(\mathrm{g} / \mathrm{s})\end{array}$ & Argon & $\begin{array}{c}\text { Arc } \\
\text { Current } \\
\text { (A) }\end{array}$ & $\begin{array}{l}\text { Distance } \\
\text { from } \\
\text { Nozzle Exit } \\
\text { (cm) }\end{array}$ \\
\hline IHF & 15.24 & 2000 & 135 & 31.7 & 720 & 55 & 52 & 6000 & 10.16 \\
\hline
\end{tabular}

\section{Test Results}

A two day test campaign, consisting of 4 total runs (two each day), was successfully conducted in IHF. Calorimeters were included in the first run (day 1) and the third run (day 2). Three different MSL grade standard PICA samples were tested along with several surface-densified and high-density PICA samples. The results and post-test analyses focusing solely on standard PICA samples are described in the following subsections.

\section{A. Calorimetry and post-test CFD analysis}

The as-run heater settings and measured heat fluxes and pressures of the test entry (IHF 290) are listed in Table 3. The measured stagnation pressures from two different runs are in good agreement with each other. However, the measured heat fluxes do not appear to be consistent with each other. Melting of slugs was observed during the exposure, which could have been the cause of this inconsistency.

Table 3: Heater settings and calorimetry data from test entry IHF 290

\begin{tabular}{|c|c|c|c|c|c|c|c|c|c|}
\hline $\begin{array}{c}\text { Arc } \\
\text { Current } \\
\text { (A) }\end{array}$ & $\begin{array}{c}\text { Main } \\
\text { Air } \\
(\mathrm{g} / \mathrm{s})\end{array}$ & $\begin{array}{l}\text { Add } \\
\text { Air } \\
(\mathrm{g} / \mathrm{s})\end{array}$ & Argon & $\begin{array}{c}\text { Arc } \\
\text { column } \\
\text { pressure } \\
(\mathrm{kPa})\end{array}$ & $\begin{array}{c}\text { Bulk } \\
\text { enthalpy } \\
(\mathrm{MJ} / \mathrm{kg})\end{array}$ & $\begin{array}{l}\text { Calorimeter } \\
\text { (dia, geom) }\end{array}$ & $\begin{array}{c}\text { Cold- } \\
\text { Wall } \\
\text { Heat Flux } \\
\left(\mathrm{W} / \mathrm{cm}^{2}\right)\end{array}$ & $\begin{array}{c}\text { Stagnation } \\
\text { Pressure } \\
(\mathrm{kPa})\end{array}$ & $\begin{array}{c}\text { Centerline } \\
\text { Enthalpy } \\
(\mathrm{MJ} / \mathrm{kg})\end{array}$ \\
\hline \multirow[t]{2}{*}{6066} & 720 & 55 & 53 & 820 & 14.2 & $\begin{array}{l}102 \mathrm{~mm}, \\
\text { hemi }\end{array}$ & 3259 & 130.9 & 50.5 \\
\hline & & & & & & $\begin{array}{c}51 \mathrm{~mm} \text {, } \\
\text { iso-q }\end{array}$ & 2611 & 130.0 & 35.5 \\
\hline 6056 & 720 & 55 & 53 & 823 & 25.5 & $\begin{array}{c}51 \mathrm{~mm} \text {, } \\
\text { iso-q }\end{array}$ & 3507 & 131.7 & 47.3 \\
\hline
\end{tabular}

The computational methodology used in the aerothermal design phase was applied to the new heater settings, and the resulting distributions are shown in Figures 8 and 9 for the hemispherical and iso-q calorimeters, respectively. Also shown in the figures are the corresponding measured data. 


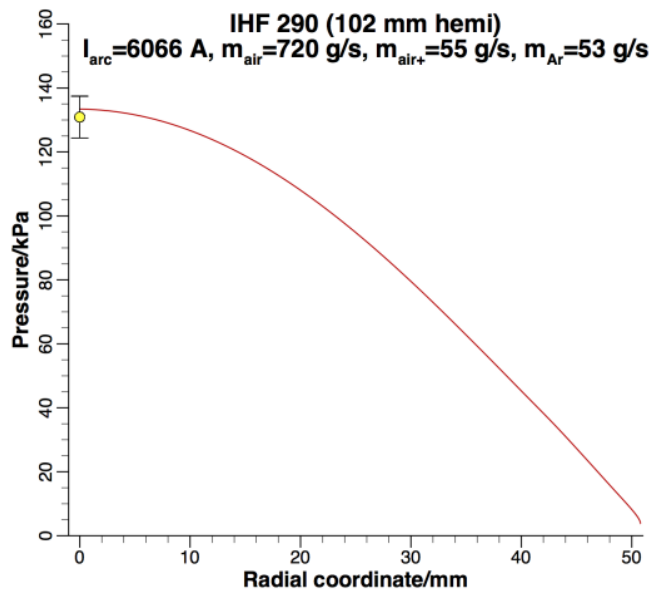

(a) Pressure

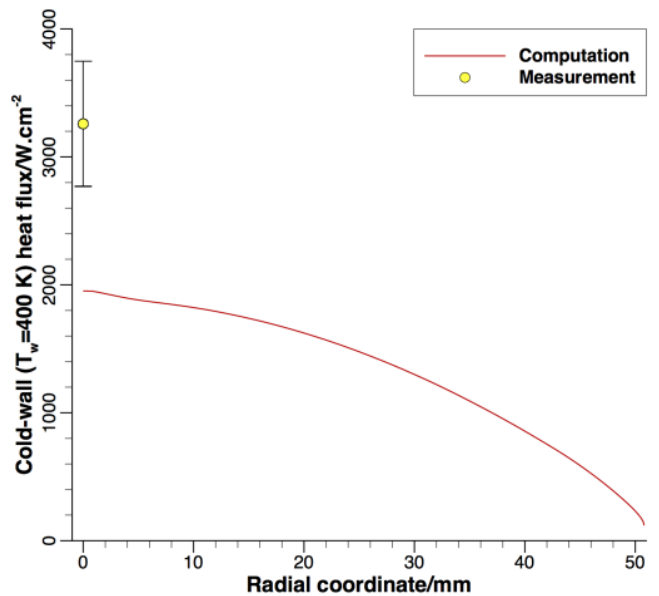

(b) Cold-wall heat flux

Figure 8. Surface distributions of: (a) pressure, and (b) cold-wall heat flux from DPLR simulations for the $102 \mathrm{~mm}$ (dia) hemispherical slug calorimeter used in IHF 290 (Table 3). Uncertainties of $\pm 5 \%$ and $\pm 15 \%$ have been assumed for pressure and heat flux measurements, respectively.

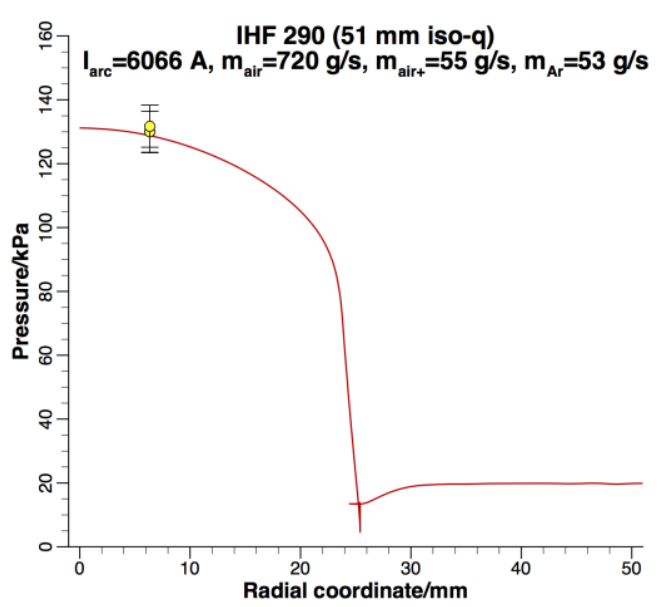

(a) Pressure

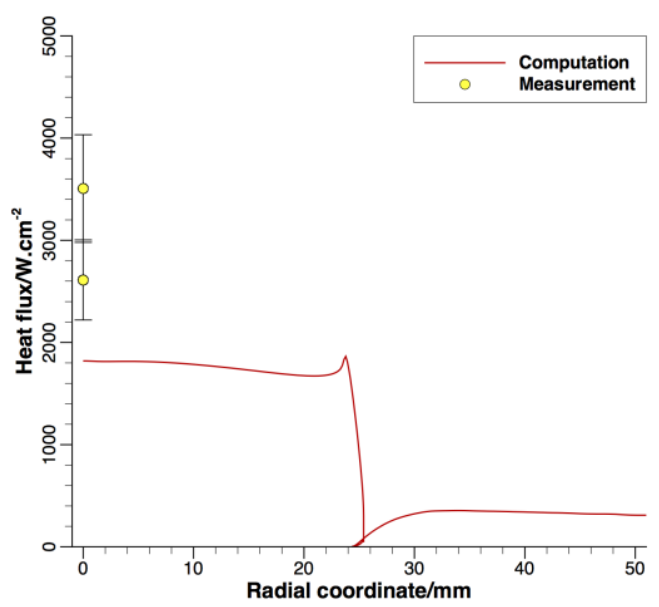

(b) Cold-wall heat flux

Figure 9. Surface distributions of: (a) pressure, and (b) cold-wall heat flux from DPLR simulations for the $51 \mathrm{~mm}$ (dia) iso-q slug calorimeter used in IHF 290 (Table 3). Uncertainties of $\pm 5 \%$ and $\pm 15 \%$ have been assumed for pressure and heat flux measurements, respectively.

Although the agreement with pressure measurements is good for both calorimeters, the predicted heat fluxes are significantly below measurements. In order to verify the computational process, which has been anchored to several cases in the historical database of measurements in the IHF, an additional case was selected from a previous test, IHF 216 with similar heater settings as the present test. The heater setting and calorimetry data from one run of this entry are shown in Table 4. The heater setting is identical to the one used in the aerothermal design phase. The predicted distributions of pressure and cold wall heat flux are shown in Figure 13. There is excellent agreement between measurement and prediction.

Table 4: Additional heater setting and calorimetry data from test entry IHF 216

\begin{tabular}{ccccccccc}
\hline \hline $\begin{array}{c}\text { Arc } \\
\begin{array}{c}\text { Current } \\
(\mathrm{A})\end{array}\end{array}$ & $\begin{array}{c}\text { Main } \\
\text { Air } \\
(\mathrm{g} / \mathrm{s})\end{array}$ & $\begin{array}{c}\text { Add } \\
\text { Air } \\
(\mathrm{g} / \mathrm{s})\end{array}$ & $\begin{array}{c}\text { Argon } \\
(\mathrm{g} / \mathrm{s})\end{array}$ & $\begin{array}{c}\text { Arc column } \\
\text { pressure } \\
(\mathrm{kPa})\end{array}$ & $\begin{array}{c}\text { Calorimeter } \\
(\mathrm{dia}, \mathrm{geom})\end{array}$ & $\begin{array}{c}\text { Cold-Wall } \\
\text { Heat Flux } \\
\left(\mathrm{W} / \mathrm{cm}^{2}\right)\end{array}$ & $\begin{array}{c}\text { Stagnation } \\
\text { Pressure } \\
(\mathrm{kPa})\end{array}$ & $\begin{array}{c}\text { Centerline } \\
\text { Enthalpy } \\
(\mathrm{MJ} / \mathrm{kg})\end{array}$ \\
\hline 5985 & 740 & 55 & 54 & 868 & $\begin{array}{c}102 \mathrm{~mm}, \\
\text { hemi }\end{array}$ & $\begin{array}{c}1991, \\
2090\end{array}$ & $\begin{array}{c}132.1, \\
132.8\end{array}$ & 31.0, \\
\hline
\end{tabular}




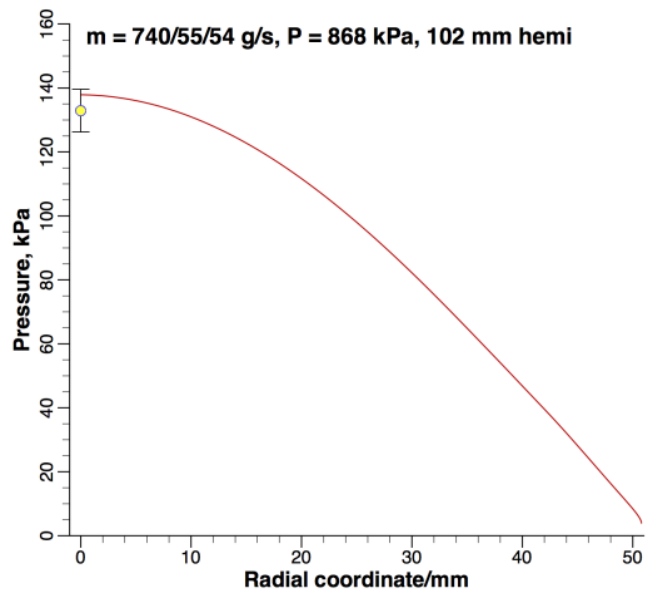

(a) Pressure

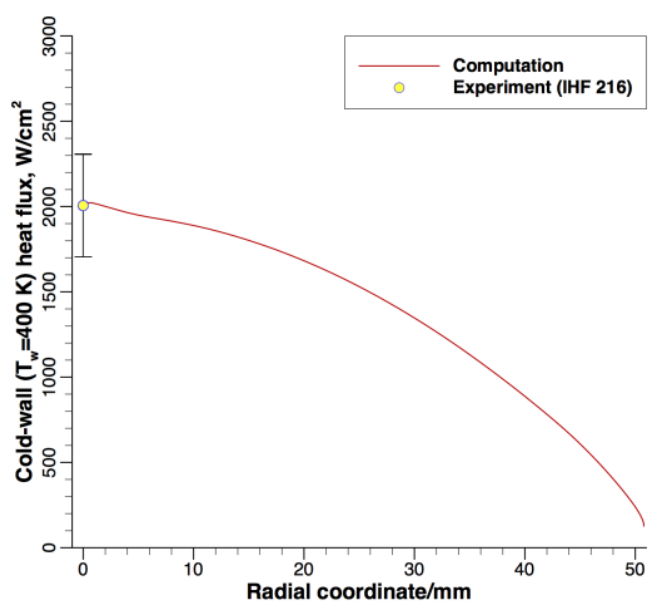

(b) Cold-wall heat flux

Figure 10. Surface distributions of: (a) pressure, and (b) cold-wall heat flux from DPLR simulations for the $102 \mathrm{~mm}$ (dia) hemispherical slug calorimeter used in IHF 216 (Table 4). Uncertainties of $\pm 5 \%$ and $\pm 15 \%$ have been assumed for pressure and heat flux measurements, respectively.

Comparing the results for the hemisphere (Figure 10) with those from preliminary design computations for the iso-q shape (Figure 4), the heat fluxes are consistent with the scaling in Eq. 2, which gave us confidence in the results of the computational method. The final test of the CFD results lies in the computation of the thermal response of the material to the predicted heat flux distribution.

\section{B. Performance of standard PICA samples}

Three MSL-grade PICA samples were tested in different runs. Figure 11 shows the top view and side view images of one of the PICA test samples prior to testing. Based on the calculations and recommendation from the FIAT thermal response model, the samples were exposed for approximately 20 seconds. Figure 12 shows one of the samples during plasma exposure. The sample was kept about $10.16 \mathrm{~cm}$ (4-inches) away from the nozzle exit. At approximately 20 seconds the sample was removed from the plasma-stream. The top view and side view images of the sample after the exposure are shown in Figure 13. All the standard PICA samples performed very well during the arcjet plasma exposure. There was no evidence of spallation or any other damage during the test. Pre-test and post-test computed tomography (CT) scans were obtained for some of the samples. The images of a pristine (untested) PICA samples as well as arcjet tested samples are shown in Figure 14. It is evident from the CT scan images that ablation is very uniform and controlled in the PICA material. No unusual or concerning features or cracks were observed at the ablated surface or internally in the PICA material.
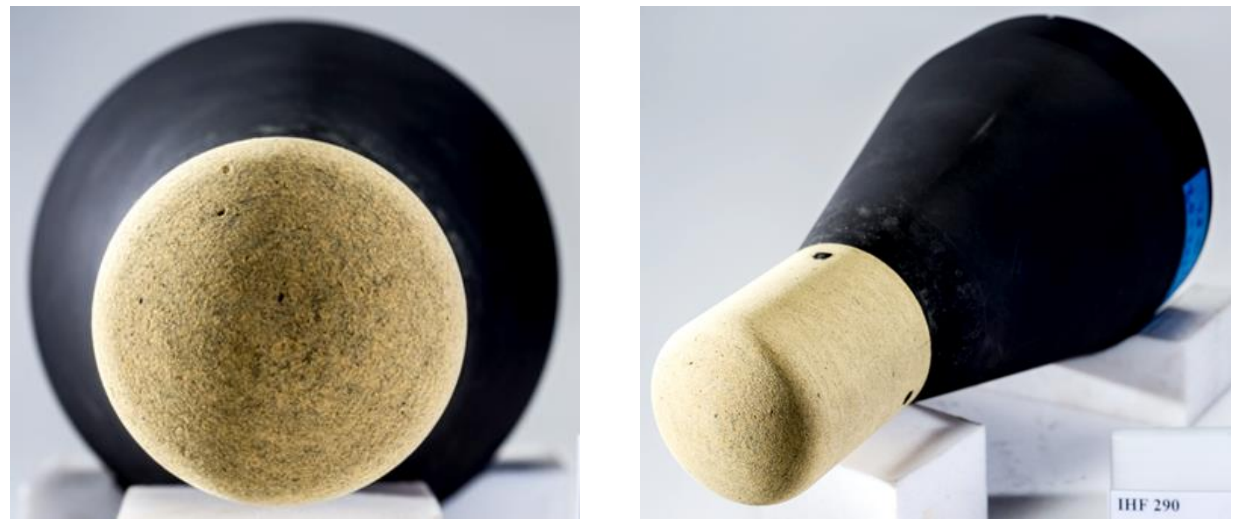

Figure 11: Top view and side view of PICA samples prior to arcjet test. 

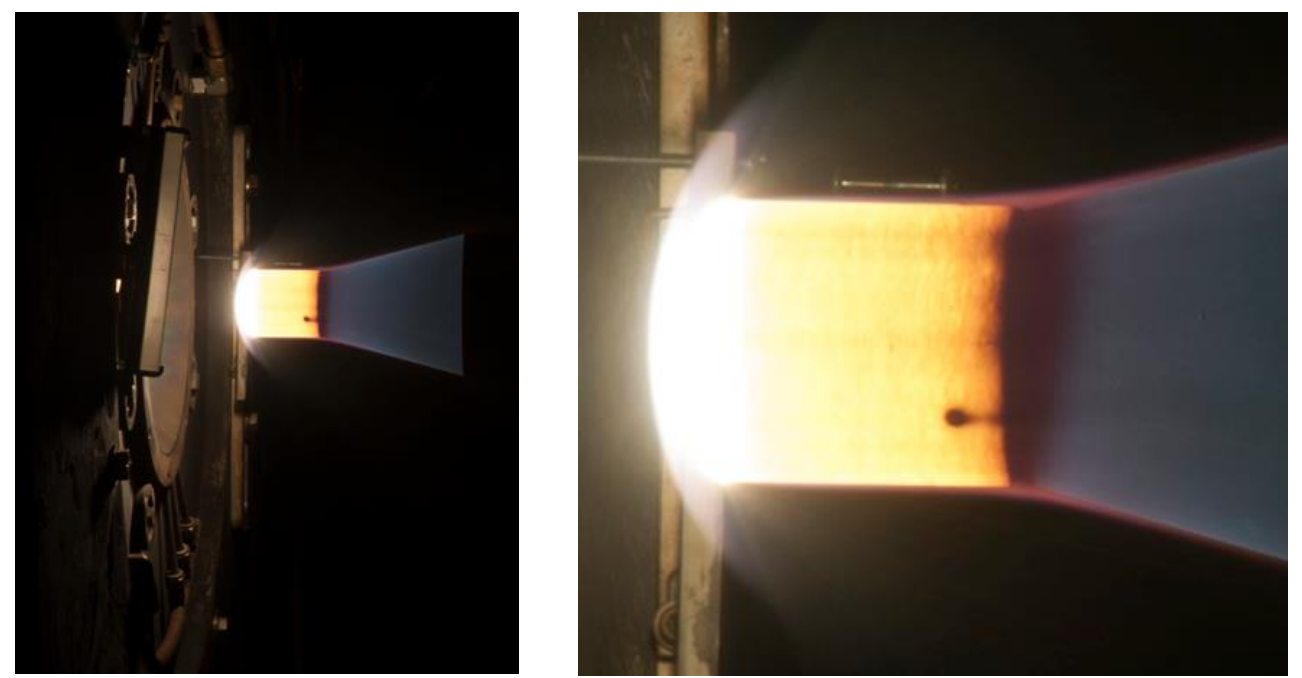

Figure 12. Top view and side view of PICA samples during the arcjet test
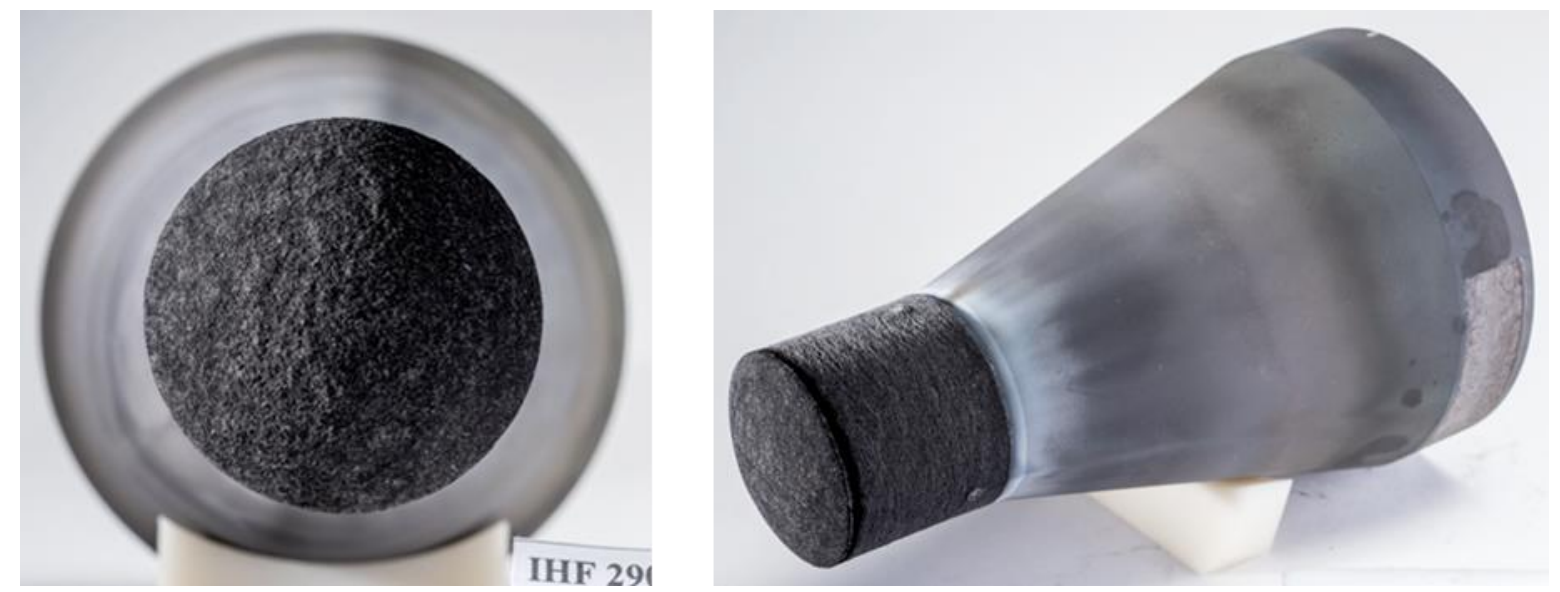

Figure 13: Top view and side view of PICA samples after 20 second exposure to arcjet plasma.

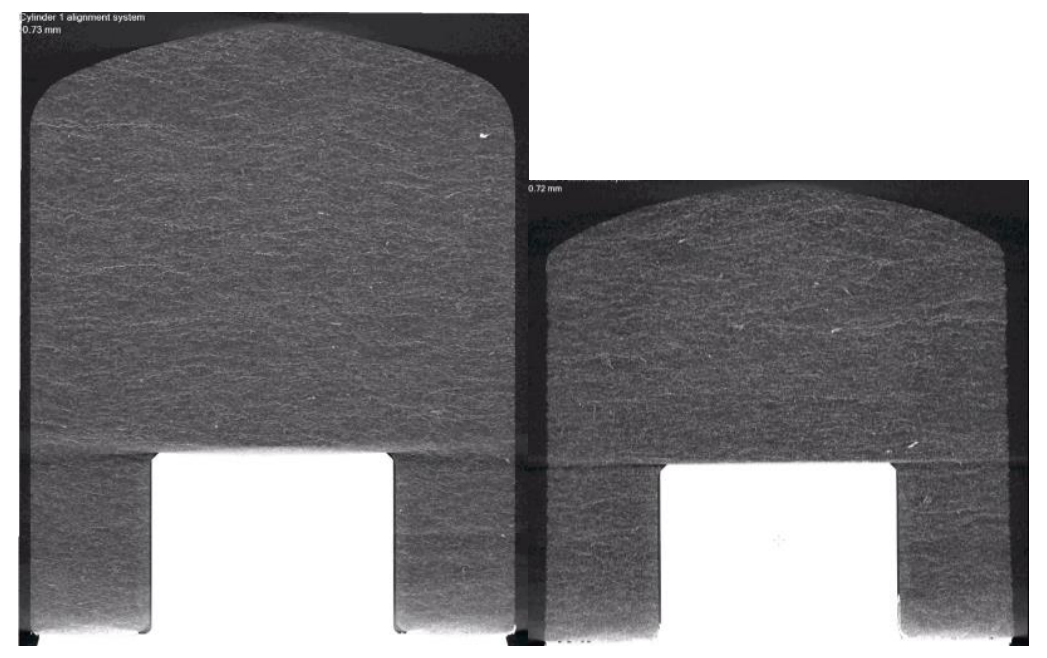

Figure 14: Pre-test and post-test CT scan images. 


\section{Surface temperature measurements}

Measurements from optical pyrometers for temperature measurements at the stagnation surface and sidewall were obtained for all three standard PICA samples. The data for the first PICA sample is shown in Figure 15. The stagnation surface turned out to be significantly hotter than the measurement limit of pyrometer and it saturated at $3000^{\circ} \mathrm{C}$. FIAT simulations predict values $>3300^{\circ} \mathrm{C}$ at stagnation surface. The side wall temperatures are in the range of $1600-1700^{\circ} \mathrm{C}$, which would cause recession and reduction in the sample diameter. The data from the other two samples are similar; stagnation surface temperature exceeded the $3000^{\circ} \mathrm{C}$ limit in every sample and hence, could not be measured. The infra-red (IR) camera also reached its saturation limit at the stagnation surface, therefore, IR data could not be obtained for surface temperature.

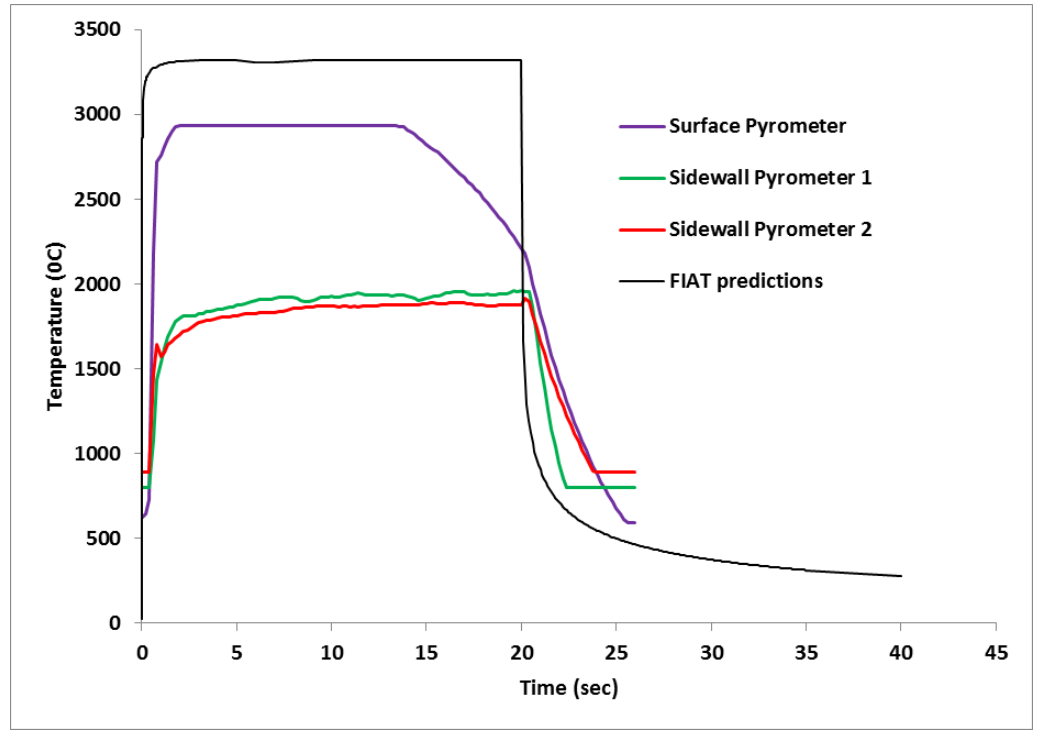

Figure 15: Temperature data from pyrometers and predictions.

\section{Recession measurements}

Pre and post-test shapes were measured by a laser scans in two perpendicular planes (designated as $\mathrm{X}$ and $\mathrm{Y}$ ) passing through the geometric axis. Figure 16 shows a representative graphic of an ablated surface (yellow) with colored vectors connecting the ablated shape to the initial shape. The scan data from the two planes are collected in Figure 17. Side-wall recession reduces the body diameter, which results in tapering of the sides and a decrease in the shoulder radius. 


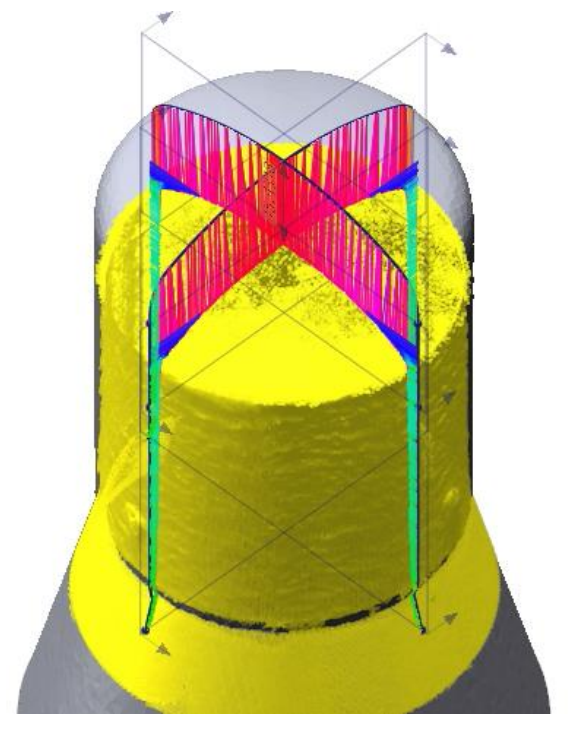

Figure 16. Laser scan graphic with vectors from initial to ablated surfaces in two perpendicular (X and Y) planes.

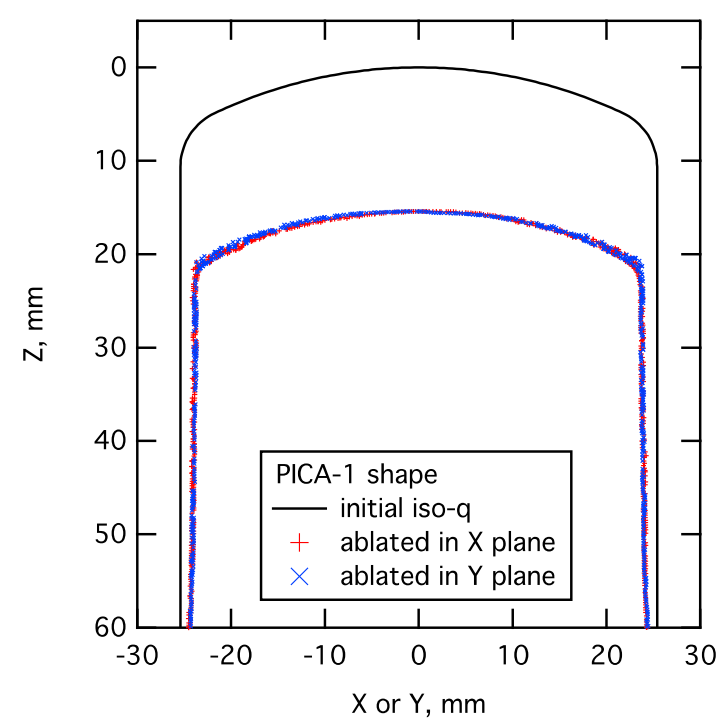

Figure 17. Representative pre- and post-test shapes. Centerline recession is $15.5 \mathrm{~mm}$.

Centerline recession is the vertical distance between the ablated and initial surfaces. Table 5 summarizes the results from the three PICA tests. Exposure duration and recession varied; however the calculated average recession rate is consistent to within $4 \%$. Average recession obtained from CT measurements is $15.62 \mathrm{~mm}$ which is consistent with the data obtained by laser scans.

The sample densities also varied, and are all above the nominal PICA value of $0.274 \mathrm{~g} / \mathrm{cm}^{3}$. In general, recession rate is inversely proportional to density. If the recession data are scaled by initial density, then, as shown in the final column of Table 5, the average mass loss rate varies by less than $1 \%$.

The data From Figure 17 are re-plotted in Figure 18 with the initial shape displaced downward to the ablated surface. The latter plot shows that the nose radius is almost unchanged (as expected for an iso-q shape), and the diameter decreases by about $7 \%$.

Table 5. Sample exposure duration and ablation data

\begin{tabular}{cccccc}
\hline Sample & $\begin{array}{c}\text { Exposure } \\
\text { Duration }\end{array}$ & $\begin{array}{c}\text { Centerline } \\
\text { Recession }\end{array}$ & $\begin{array}{c}\text { Initial Density } \\
( \pm 0.003 \\
\mathrm{g} / \mathrm{cm} 3)\end{array}$ & $\begin{array}{c}\text { Calculated Average } \\
\text { Recession Rate }\end{array}$ & $\begin{array}{c}\text { Calculated } \\
\text { Average Mass } \\
\text { Loss Rate }\end{array}$ \\
\hline PICA-1 & $19.05 \mathrm{~s})$ & $( \pm 0.25 \mathrm{~mm})$ & 0.278 & 0.789 & 0.0219 \\
\hline PICA-2 & 20.2 & 15.5 & 0.28 & 0.777 & 0.0218 \\
\hline PICA-3 & 20.15 & 15.7 & 0.286 & 0.759 & 0.0217 \\
\hline
\end{tabular}




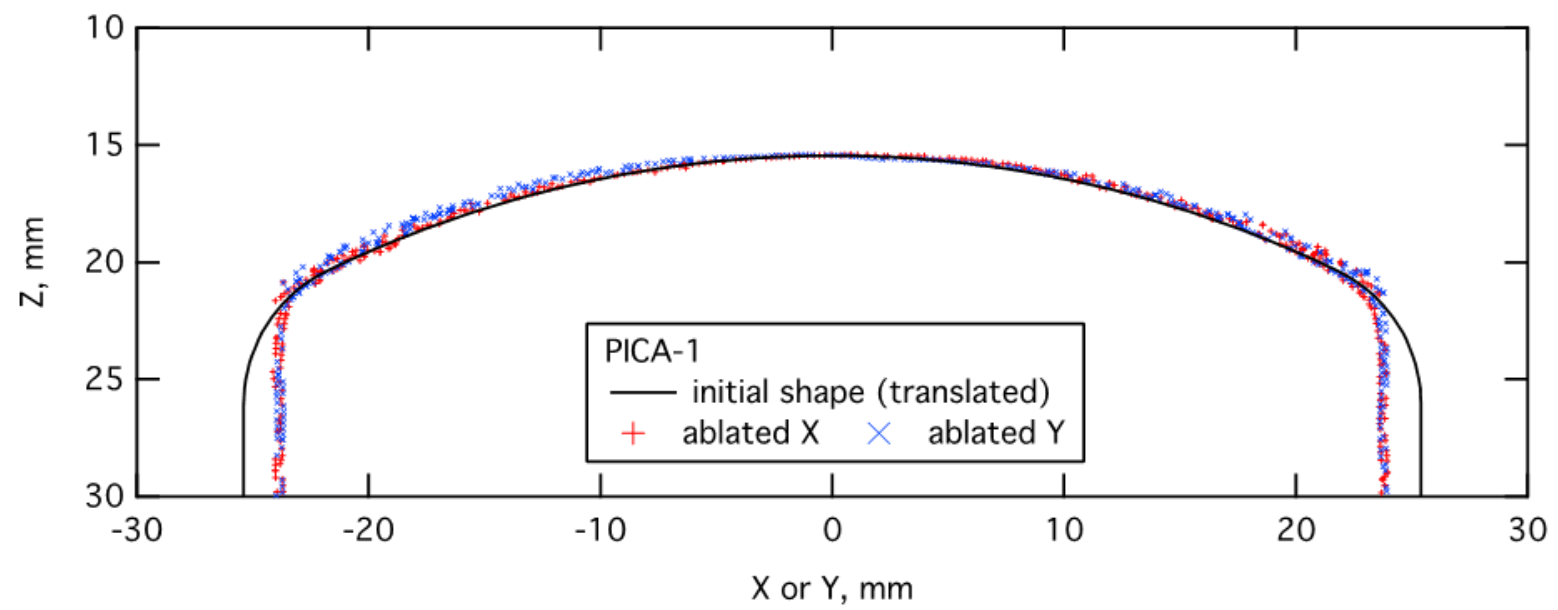

Figure 18. Comparison of initial and final surface curvatures.

\section{E. Post-test computational analysis: Test article}

Having gained confidence in the numerical simulation, computations were performed for the test article at the heater conditions given in Table 3. Computations for the test article were performed with two different wall boundary conditions: (a) wall temperature fixed at $400 \mathrm{~K}$, and (b) wall temperature allowed to float with imposition of radiative equilibrium (albeit without conduction through the thickness). Simulations were performed for both the initial and final shapes (Figure 17). The predicted surface pressure and heat flux distributions are shown in Figures 19 and 20 for the initial and final shapes, respectively. Since the radius of curvature for ablated shape is identical to the initial shape of the sample, no significant difference was observed in the heatflux values for ablated shape. However, due to recession there is a decrease in static pressure (the distance from nozzle exit plane increases), which reflects in $~ 5 \%$ decrease in stagnation pressure as shown in Figure 20.

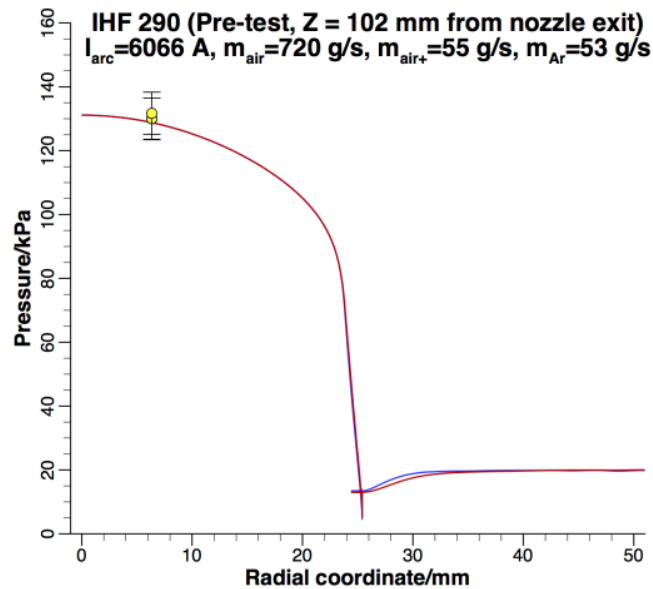

(a) Pressure

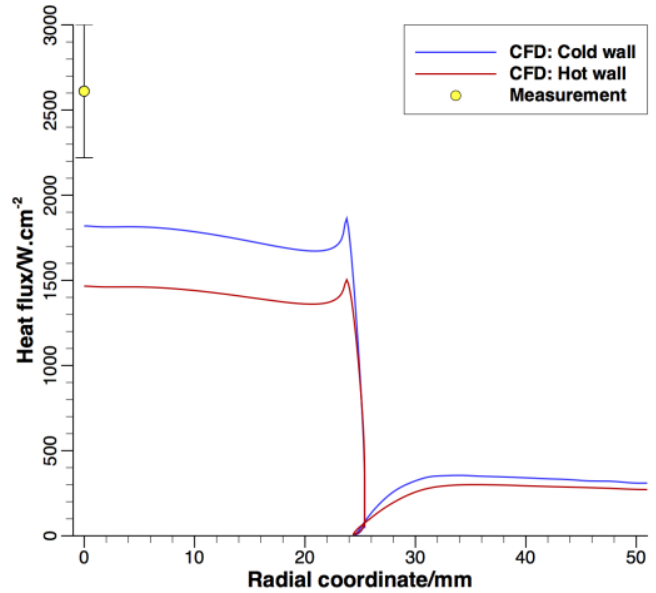

(b) Cold-wall heat flux

Figure 19. Surface distributions of: (a) pressure, and (b) heat flux from DPLR simulations for the initial shape of test article at conditions given in Table 4. Hot-wall computations assume a surface emissivity of 0.85 and heat conduction through the thickness of the material is neglected. 


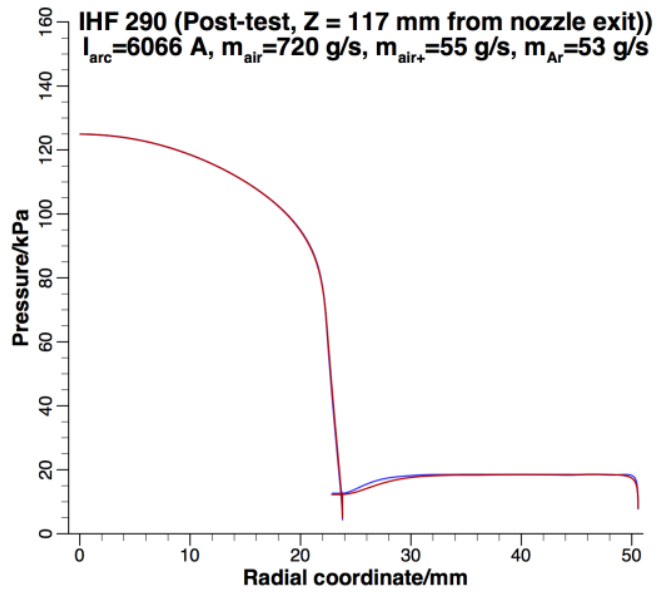

(a) Pressure

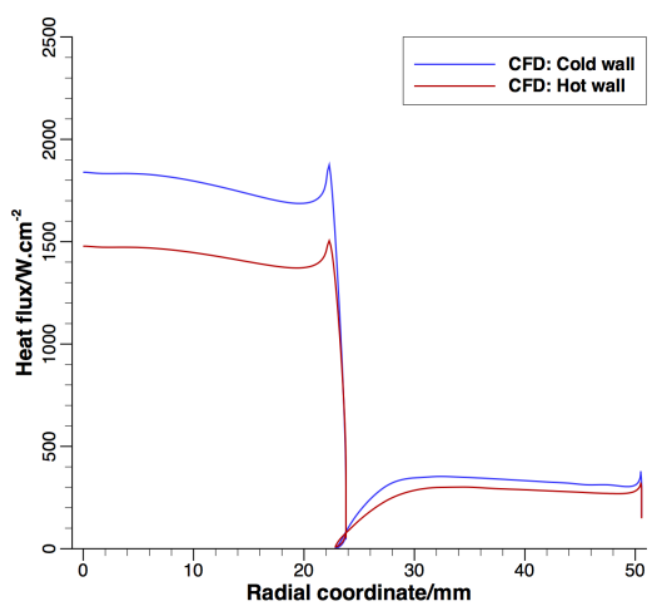

(b) Cold-wall heat flux

Figure 20. Surface distributions of: (a) pressure, and (b) heat flux from DPLR simulations for the final (ablated) shape of the test article at conditions given in Table 4. The post-test shape is a photographically scaled $(0.937$-scale) of the original shape, and the freestream conditions in the computation corresponding to $15.5 \mathrm{~mm}$ movement away from the nozzle exit plane. Hot-wall computations assume a surface emissivity of 0.85 and heat condition through the thickness of the material is neglected.

\section{F. Post-test computational analysis: Material thermal response}

FIAT calculations were performed using the nominal hot-wall environments from DPLR and also with $\pm 10 \%$ uncertainty applied to the heat transfer coefficient. Boundary conditions were linearly interpolated in time between initial values for the unablated shape (Figure 19) and final values for the fully ablated shape (Figure 20).

Figure 21 presents the predicted stagnation point recession histories for these three heating levels. The data fall slightly below the range of recession predicted by the PICA model. One factor that contributes to the over-prediction is the above-nominal virgin density of the MSL-grade PICA used in this work. The data points rise by a few percent if corrected for differences in initial density. The standard PICA model appears to be conservative for predicting recession at high heat flux.

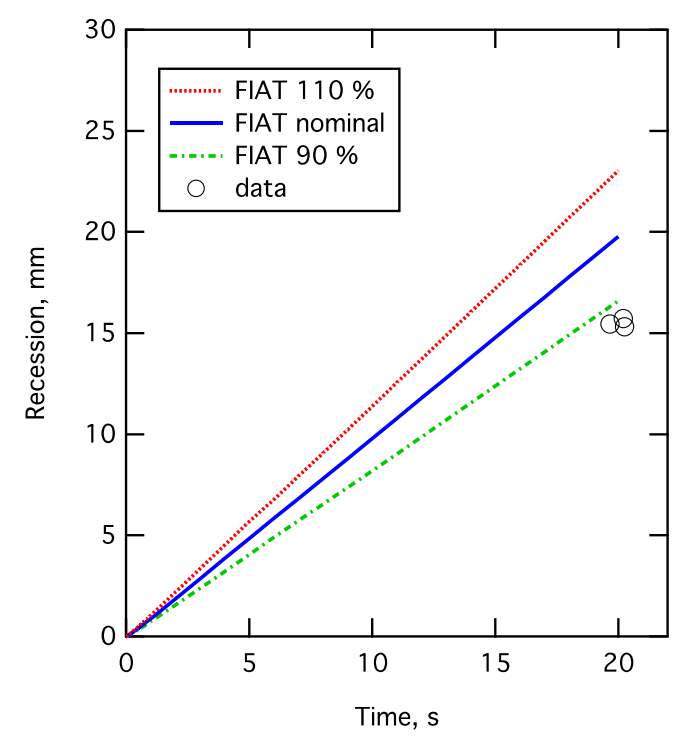

Figure 21. Recession predictions for standard PICA compared with data. 


\section{Conclusion}

The current arcjet tests on MSL grade PICA material demonstrated the potential of this material at conditions beyond the established limits of $1500 \mathrm{~W} / \mathrm{cm}^{2}$ heat flux and $1.0 \mathrm{~atm}$ pressure. The material not only survived but performed exceptionally well, with consistent performance across multiple samples, at the estimated heat-flux of 1800 $\mathrm{W} / \mathrm{cm}^{2}$ and pressure of $130 \mathrm{kPa}$. While we had problems in obtaining consistent calorimeter data for the heat flux values due to melting of slugs, we are confident in the aerothermal computational predictions, as, when same aerothermal model was applied to similar heater settings in a past test, it yielded good agreement with calorimetry. The predicted stagnation pressure values from aerothermal analysis were in good agreement with measured values. The thermal response model (FIAT) predictions for recession show there is slight over prediction compared to measured values of recession. More tests at the heat flux ranging from 1500 to $2500 \mathrm{~W} / \mathrm{cm}^{2}$ as well as reliable calorimetry are needed to establish and validate the PICA thermal response model at high heat flux, and expand the performance envelope. The present results show a promise to significantly change the design space for various missions, where a low density TPS material like PICA could be selected for thermal protection. These missions may include sample return missions from various destinations like Mars, comets and asteroids, human space missions to Mars as well as science missions to outer planets like Saturn, Uranus and Neptune.

\section{Future Work}

PICA can be considered as a family of materials rather than a single composition. Stardust, OSIRIS-REx and MSL have all flown slightly different variants of PICA and the viable compositional trade space for PICA has not been fully explored. The objective for the future test series would be to investigate the performance limits for variants of PICA. Based on the success of current arcjet testing for MSL grade PICA, we plan to conduct additional tests with various facility settings in order to achieve varying values of heat-flux and pressures. The plan is to achieve heat fluxes in the range of $2000 \mathrm{~W} / \mathrm{cm}^{2}-3500 \mathrm{~W} / \mathrm{cm}^{2}$, pressures of $1.5 \mathrm{kPa}-2.0 \mathrm{kPa}$ and shear of $400 \mathrm{~Pa}-1000 \mathrm{~Pa}$. All compositions evaluated will be compared to baseline MSL PICA. It is anticipated that improvements to key properties of PICA will yield a TPS with expanded capabilities and enable future science and human missions.

\section{Acknowledgments}

The authors are grateful to TSM branch managers Thomas Squire (Chief, TSM Branch) and Joseph Conley for his support and encouragement of this work. The authors thank Imelda Terrazas-Salinas, Enrique Carballo and Joseph Mach, the engineers and staff from arcjet test facility and model fabrication laboratory for sample preparation and successful completion of the tests. The authors also thank Jose Chavez Garcia, Keith Peterson, Kristina Skokova and Megan McDonalds for helpful discussions and participation in sample design. The critical financial support provided by NASA-SCAP for the arc-jet operational capability at NASA Ames Research Center is gratefully acknowledged.

\section{References}

1 Tran, H., Johnson, C., Rasky, D., Hui, F., Chen, Y.-K., and Hsu, M., "Phenolic Impregnated Carbon Ablators (PICA) for Discovery Class Missions," AIAA Paper 96-1911, June 1996.

2 Trumble, K. A., Ioana, C., Sepka, S., Jenniskens, P., and Winter, M., "Postflight Aerothermal Analysis of the Stardust Sample Return Capsule," Journal of Spacecraft and Rockets, 47(5), 2010, pp. 765-774.

3 Lockwood, M.K., "Introduction: Mars Science Laboratory: The next generation of Mars Landers," Journal of Spacecraft and Rockets, 43(2), 2006, p. 257.

4 K. Berry, B. Sutter, A. May, K. Williams, B.W. Barbee, M. Beckman, B. Williams, "OSIRIS-REx Touch-And-Go (TAG) Mission Design and Analysis", AAS Guidance And Control Conference \#36, Breckenridge, CO, Paper No. AAS 13-095

5 Chambers, A., and Rasky, D., "NASA and SpaceX Work Together," NASA ASK Magazine, 40, Fall 2010, URL: www.nasa.gov/pdf/489060main_ASK_40_Fall_2010.pdf.

6 Beerman, A. and Stackpoole, M., "Recent Arc-Jet Testing of Phenolic Impregnated Carbon Ablator (PICA) - Paving the Way for New Mission Possibilities," $38^{\text {th }}$ Annual Conference on Composites, Materials, and Structures by the Ceramic, Metal and Carbon Composites Committee, Cocoa Beach, FL, January 28, 2014.

7 Tito, D. A., et al., "Feasibility Analysis for a Manned Mars Free-Return Mission in 2018," Proceedings IEEE Aerospace Conference, DOI: 10.1109/AERO.2013.6497413, Mar. 2013.

8 Zoby, E. V., and Sullivan, E. M., "Effects of Corner Radius on Stagnation-Point Velocity Gradients on Blunt Axisymmetric Bodies," Journal of Spacecraft and Rockets, Vol. 3, No. 10, pp. 1567-1567, 1966. 
9 Prabhu, D., Saunders, D., Oishi, T., Skokova, K., Santos, J., Fu, J., Terrazas-Salinas, I., Carballo, E., and Driver, D., "CFD Analysis Framework for Arc-Heated Flowfields, I: Stagnation Testing in Arc-jets at NASA ARC," AIAA Paper 2009-4080, 41 ${ }^{\text {st }}$ AIAA Thermophysics Conference, San Antonio, TX, June 22-25, 2009.

${ }_{10}$ Wright, M. W., White, T., and Mangini, N., "Data Parallel Line Relaxation (DPLR) Code User Manual Version 4.01.1," NASA/TM-2009-215388, 2009.

${ }^{11}$ Chen, Y.-K., and Milos, F. S., "Ablation and Thermal Response Program for Spacecraft Heatshield Analysis," Journal Spacecraft and Rockets, 36(3), 1999, pp. 475-483.

${ }^{12}$ Milos, F. S., and Chen, Y.-K., "Comprehensive Model for Multicomponent Ablation Thermochemistry," AIAA Paper $97-$ 0141, Jan. 1997

${ }^{13}$ Fay, J A, and Riddell, F R, “Theory of Stagnation Point Heat Transfer in Dissociated Air," J. Aeronautical Sciences, 25(2), 1958, pp. 73-85, 121

${ }^{14}$ Zoby, E. V., "Empirical Stagnation-Point Heat-Transfer Relation in Several Gas Mixtures," NASA TN D-4799, Oct. 1968.

15 Milos, F. S., and Chen, Y.-K., "Ablation Predictions for Carbonaceous Materials Using Two Databases for Species Thermodynamics," Journal of Spacecraft and Rockets, 50(2), 2013, pp. 245-255. 